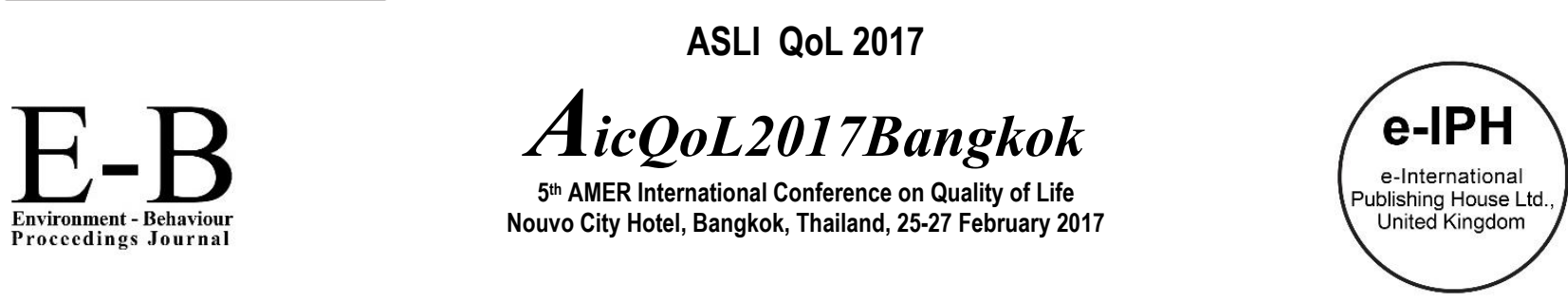

\title{
The Different Analysis of Carbon Footprint according to Life Cycle Assessment of Furniture Type: A case study of the Table
}

\author{
Karuna Kwangsawat ${ }^{1 *}$, Yanin Rugwongwan ${ }^{2}$ \\ 1 Arch D. Student, Faculty of Architecture, King Mongkut's Institute \\ of Technology Ladkrabang (KMITL), Thailand. \\ 2 Asst. Prof. PhD program in a school of Interior Architecture, Faculty of Architecture, \\ King Mongkut's Institute of Technology Ladkrabang (KMITL), Thailand.
}

\begin{abstract}
This article attempts to present the process of preparing an analysis on differential Carbon Footprint of each furniture types according to their product life cycle. The case study on one type of furniture namely "Tables" is to assessment the environmental effect of the production process and the method of raw material selection in furniture manufacturing and by using carbon footprint is an indicator of its effect. By using different types of furniture and product grouping furniture to indicate and calculate the quantity of carbon footprint. During the study customer's perception in response to environmentally friendly products, the result is expected to be the quantity of carbon footprint could be classified into three levels, i.e. furniture with the high, the medium and the low level of carbon footprints.
\end{abstract}

Keywords: Carbon Footprint; Life Cycle Assessment, Furniture Design, Environmental.

ISSN: 2398-42870 2017. The Authors. Published for AMER ABRA by e-International Publishing House, Ltd., UK. This is an open access article under the CC BYNC-ND license (http://creativecommons.org/licenses/by-nc-nd/4.0/). Peer-review under responsibility of AMER (Association of Malaysian Environment-Behaviour Researchers), ABRA (Association of Behavioural Researchers on Asians) and cE-Bs (Centre for Environment-Behaviour Studies), Faculty of Architecture, Planning \& Surveying, Universiti Teknologi MARA, Malaysia.

\subsection{Introduction}

At present, a lot of attention was aware to the industrial sector on the subject of environmental protection. (Sergio Silva Braga Junior, 2015) The design concept that involved on the environmentally friendly products has become more significant to the development of Economic, social and environmental sectors. The design concept is to improve the quality of both products and manufacturing industry, to be able to compete at the level of local and international markets. The environmentally friendly products' design concept is emphasised to reduce the environmental issues by surveying the product from the beginning of its life cycle to the end. By using this concept surveying the whole picture of the problem and its effects from the product manufacturing process shall be determined which helps to enable us to have better product development and environmental protection.

Since there are numerous kinds of materials to be used in the production process, the priority of this environmental assessment is the selection of raw material. (Maria d Bovea, 2004) In this article, the method of determining the different types of table furniture is by using the criteria of both raw materials to be used to produce that table and the production process, which depending on the product life cycle. The product life cycle assessment techniques are to assess the whole quantity of pollution and the environmental issue, which occur during the process of manufacturing and servicing from raw material sourcing, production, transportation, consuming of the productions until product disposal. (Scientific Applications International Corporation (SAIC) 11251 Roger Bacon Drive Reston, 2006) The most popular raw materials, to be used in the furniture industry to produce table, are the natural material. Natural raw materials can be specified in two categories, natural woods and engineering wood (PB, MDF). The carbon footprint assessment on the raw materials to be used in furniture industry, start from wood selection and processing until the end of product life cycle which is the material waste disposal management. (Maria d Bovea, 2004) In this study, Focus on the wooden board. Because it is commonly used in the manufacture of furniture on the tables. There is a market in Thailand and abroad.

\footnotetext{
${ }^{*}$ Corresponding author. Tel:

E-mail address: kwangsawath@yahoo.com
}

ISSN: 2398-4287@ 2017. The Authors. Published for AMER ABRA by e-International Publishing House, Ltd., UK. This is an open access article under the CC BYNC-ND license (http://creativecommons.org/licenses/by-nc-nd/4.0/). Peer-review under responsibility of AMER (Association of Malaysian Environment-Behaviour Researchers), ABRA (Association of Behavioural Researchers on Asians) and CE-Bs (Centre for Environment-Behaviour Studies), Faculty of Architecture, Planning \& Surveying, Universiti Teknologi MARA, Malaysia.

DOl: http://dx.doi.org/10.21834/e-bpj.v2i5.654 


\subsection{Literature Review}

\subsection{The Carbon Footprint principle}

Carbon Footprint The deal calls for the implementation of greenhouse gas management within the category (Domestic actions) instead of purchasing carbon credits (Carbon Credit) contribute to the development Carbon Footprint up. The objective is to evaluate the amount of greenhouse gas emissions. To encourage the reduction of emissions. From improving the efficiency of production processes. Energy and Resources The waste disposal Management of transport and distribution. As well as the procurement and selection of containers. Aimed at reducing global warming and climate change. (Schwartz)

The carbon footprint is not just carbon dioxide only. There are also other gases, However, because carbon dioxide is a greenhouse gas that has kind of let up. The use of gas as a real hot glass. The definition of carbon footprint refers to the amount of greenhouse gas emissions by six types of greenhouse gases, the main considerations in the Kyoto Protocol (Kyoto to Protocol) and carbon dioxide (CO2), methane (CH4), nitrous oxide (. N2O), hydro Fluorocarbon (HFCs) Super Fluorocarbon (PCFs) and sulfur hexafluoride fluoride (SF6) by calculating the carbon footprint. Equivalent to the amount of carbon dioxide equivalent (CO2 equivalent $\mathrm{CO} 2 \mathrm{e})$

\begin{tabular}{l|l|l|l}
\multicolumn{5}{c}{ Table. 1 The calculate Carbon Footprint simple. } \\
\hline greenhouse gas & Emissions (kg.) & The potential to cause global warming. $\left(\mathrm{Co}_{2} \mathrm{e}\right)$ & Carbon Footprint $\left(\mathrm{kg}\right.$. C $\left.\mathrm{O}_{2} \mathrm{e}\right)$ \\
\hline $\mathrm{CO}_{2}$ & 1 & 1 & $=1 \times 1=1$ \\
$\mathrm{CH}_{4}$ & 1 & 25 & $=25 \times 1=25$ \\
$\mathrm{HCFC}-123$ & 1 & 77 & $=77 \times 1=77$ \\
$\mathrm{~N}_{2} \mathrm{O}$ & 1 & 298 & $=298 \times 1=298$ \\
OFC-218 & 1 & 8,830 & $=8,830 \times 1=8,830$ \\
$\mathrm{SF}$ & 1 & 22,800 & $=22,800 \times 1=22,800$ \\
\hline
\end{tabular}

The total carbon footprint. $=1+25+77+298+8,830+22,800=32,031$

According the potential to cause global warming (CO2e) from the IPCC Report (2006) (Rattanawun, 2015)

The carbon footprint is not just emissions from energy use and waste management, including the emission of greenhouse gases from activities throughout life (Life Cycle GHG emissions), not only for the factory. It also includes some greenhouse gas emissions from activities upstream and downstream. The upstream activities (Upstream activities) means all production activities at the plant or animal raw materials, chemicals, water, energy and container. Transportation of raw materials And containers to plant The downstream activities (Downstream activities) refers to events that occurred outside the plant, including the distribution of goods to the buyer or consumer applications for managing waste from active or expired. Collectively Products from birth to death (Cradle to grave) concluded that the carbon footprint of all the activities that greenhouse gas emissions from the production of raw materials and packaging. Transportation of raw materials and containers The distribution, use and waste management after the end of its life. (Rattanawun, 2015)

\subsection{Assessing the carbon footprint of products.}

The Carbon Footprint is to assess an amount of greenhouse gases are expected to be released. Each of the products throughout the product lifecycle, from raw material acquisition, manufacturing, transport, use and manage the product remains in use. The calculations in the form of carbon dioxide are equivalent. Carbon footprint (Carbon Footprint: CF) assessment techniques to evaluate the life cycle (Life Cycle Assessment: LCA) started to be more complex. The carbon footprint comes from its assessment of the environmental impact concerning global warming. Call the ability to cause global warming (Global Warming Potential: GWP), So LCA and $C F$ are linked together by CF is the environmental impact of the assessment in LCA, but LCA also. Impact other aspects such as the depletion of resources. The occurrence of acid rain The increase in nutrients in the water. The occurrence of toxic effects on ecosystems. However, because of the technique, LCA defines general principles and specific provisions as defined alternatives, so the carbon footprint. Take the general principles of the LCA is to identify the specific requirements and identify alternatives as an alternative force. The primary analysis of the carbon footprint at the same standard.

The Carbon Footprint can evaluate multiple levels. Depending on the intended use, including the carbon footprint of products/ services. The project or organisation Summarised as follows:

1. Carbon Footprint of Products (Product carbon footprint) for the development of products that are friendly to the climate. An assessment of greenhouse gas emissions throughout the product life cycle products such as ceramic tiles for flooring. Men's cotton polo

2. Carbon Footprint of Service (Service carbon footprint) for manufactured goods to services such as hotels beverage bank to evaluate the greenhouse gas emissions from the activities of the service.

3. The carbon footprint of an organisation. (Organization carbon footprint) To create the image of an organisation that has to manage greenhouse gas emissions and environmental. An assessment has a greenhouse gas emissions from direct and indirect activities of the organisation. You can assess the extent of the three levels.

The first assessment has a greenhouse gas emissions directly.

The second is an evaluation of some greenhouse gas emissions from purchased electricity, heat, steam used in the enterprise.

Level 3 assessed some greenhouse gas emissions from indirect activity such as employee travel. Business Travel Transport services and transport raw materials. Production of raw materials Wastes management, water use. 
4. Carbon Footprint Project (Carbon footprint of Project) for a project to reduce greenhouse gas emissions. To lead to the trading of carbon credits. The estimated volume of greenhouse gas emissions from projects like reforestation. Biogas from pig farms. And the production of electricity from hydropower. (Rattanawun, 2015)

When evaluating the amount of greenhouse gas emissions is finished. Need a way to make consumers aware of the amount of carbon that comes out of that product labelling is a way to show the carbon emissions of products. This is information between producers and consumers. Each country uses a different name, such as the United Kingdom has a "Carbon Reduction Label" (Carbon Reduction Label) can tell that the producers have made a commitment to reduce the carbon footprint. France used the name "Indice Carbone" (Carbon Index) can say that the producers did not have to make a commitment to reduce the carbon footprint. In the "Carbon Footprint Label" (Carbon Footprint) can tell that the producers did not have to make a commitment to reduce the carbon footprint. Carbon labels which can be classified into four categories based on the information that is displayed on the label.

Table. 2 Labels table displays the carbon footprint of products

\begin{tabular}{|l|l}
\hline label & descriptions \\
\hline & $\begin{array}{l}\text { The label indicates lower carbon emissions (Low-carbon seal) show lower emissions of } \\
\text { carbon products in the same group. }\end{array}$ \\
\hline & $\begin{array}{l}\text { The label indicates the level of carbon (Carbon rating) showing the carbon footprint of } \\
\text { the products, such as gold, silver, and copper, or an indication of a reduction in carbon } \\
\text { emissions. It does not show the amount of carbon emitted. }\end{array}$ \\
\hline & $\begin{array}{l}\text { Carbon label size (Carbon score) shows an amount of carbon emissions as the scale of } \\
\text { the carbon footprint. }\end{array}$ \\
\hline
\end{tabular}

\subsection{Methodology}

From Fig.1 The method of this study is presented, which is the assessment of carbon footprint of the furniture manufacturing process of Thai furniture industry namely "Table."

- Seven brands of Table furniture that are available in the market.

- The raw material used for table production are used to indicate, each type of table, and to determine the quantity of carbon footprint of each type of table.

- Description of the manufacturing process, from the first step of processing the raw materials, production, transportation to storage are transportation to the wholesaler and the retailer, to the final consumer and, lastly, the waste management of the products and product disposal.

- Calculation of carbon footprint on each processing by using the base data from the centre of environmental protect. (www.tgo.br.th)

- To tabulate and grouping of the carbon footprint quantity of each type of table from low to high.

The benefits of collecting the portion of carbon footprint are to be used for references for those interested including designers, the manufactory, and most influential consumers. Moreover, the database would be useful as environmental information, and can also be beneficial as criteria for the other furniture products to be used for raw material selection. (Review, 2012)

The scope of variables Research has the type of material used in the study was a wooden board material used in the manufacture of furniture. The Natural material this can be divided into two parts: natural wood (wood) and engineering wood (PB, MDF) and the coating process of the furniture is the natural veneer, the coating. And the science of wood is Laminated, Melamine 


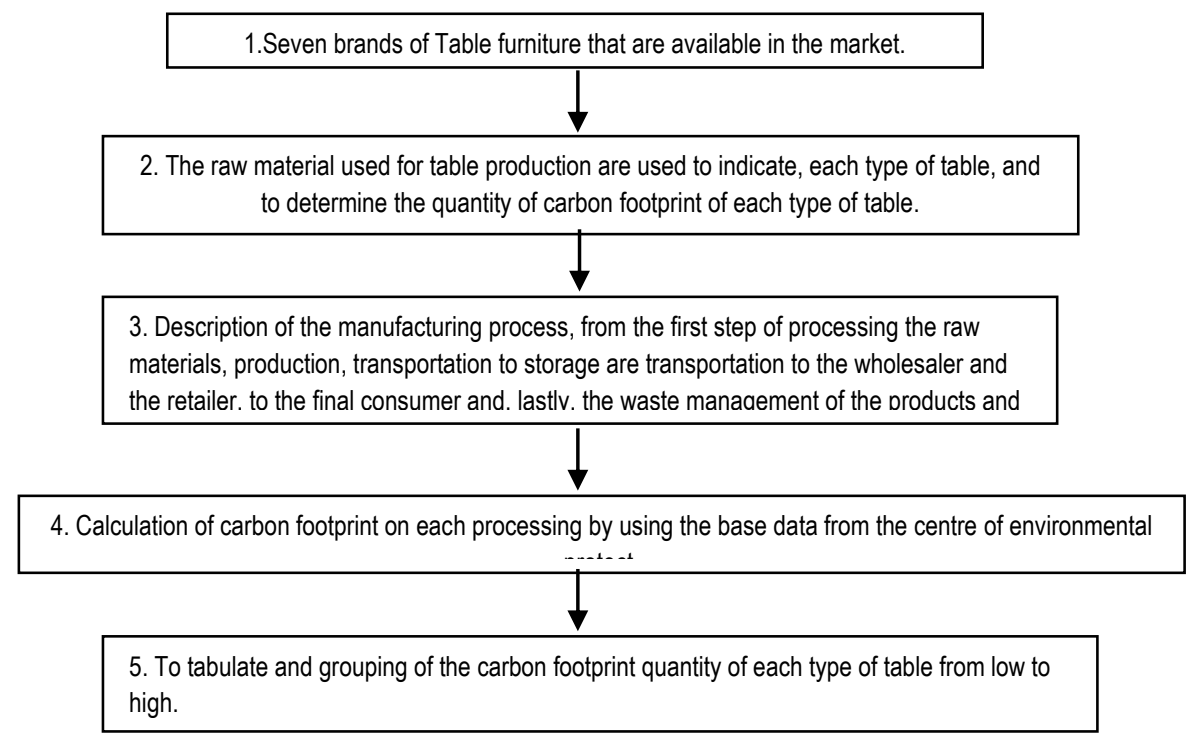

Fig. 1 Methodology followed in the studying and analysis of carbon footprint process the furniture production in the Thailand furniture sector.

3.1 The process of assessing the carbon footprint of the manufacturing process of the table. The use of natural wood as a raw material.

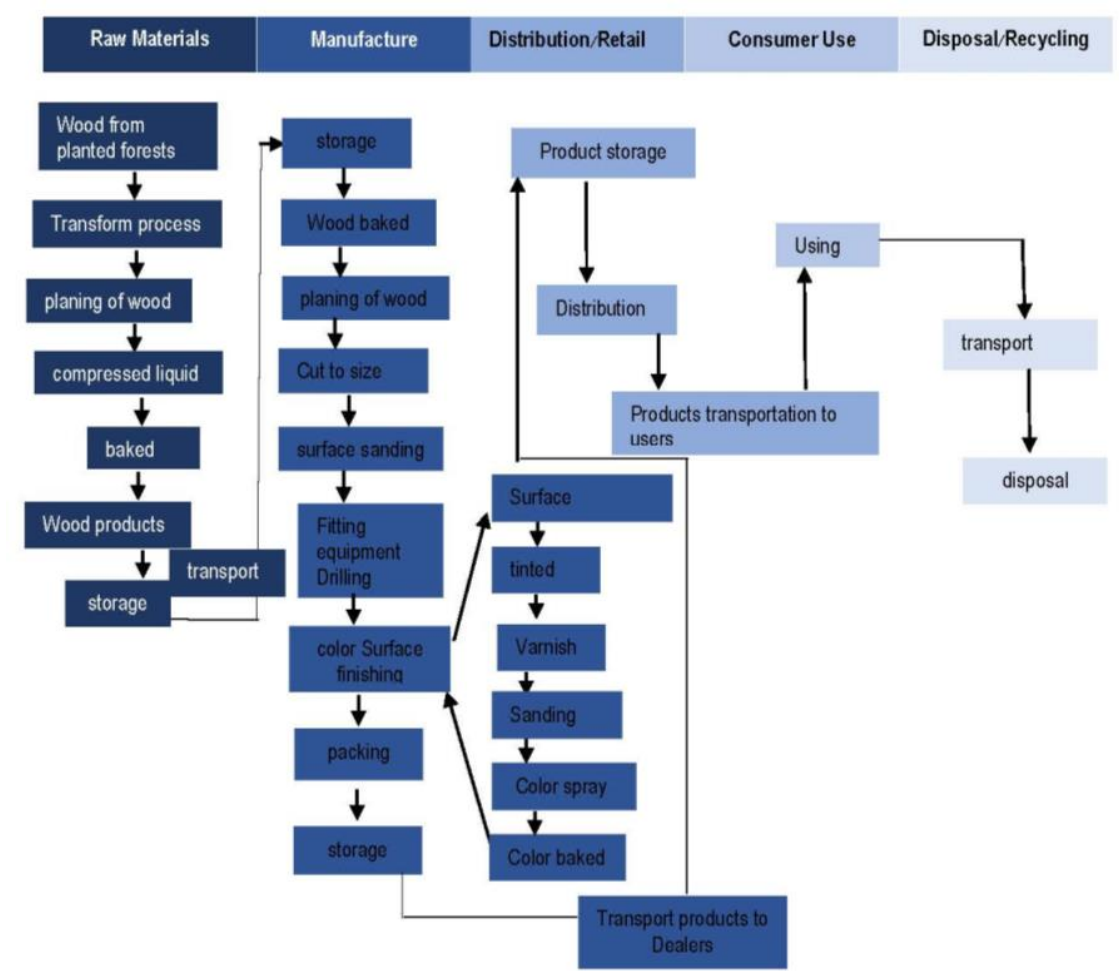

Fig. 2 Steps to assess the carbon footprint of the manufacturing process of the table. The use of natural wood as a raw material.

3.2 The method of determining the carbon footprint of the manufacturing process of the table used the medium density board covered with veneer as the raw material. 


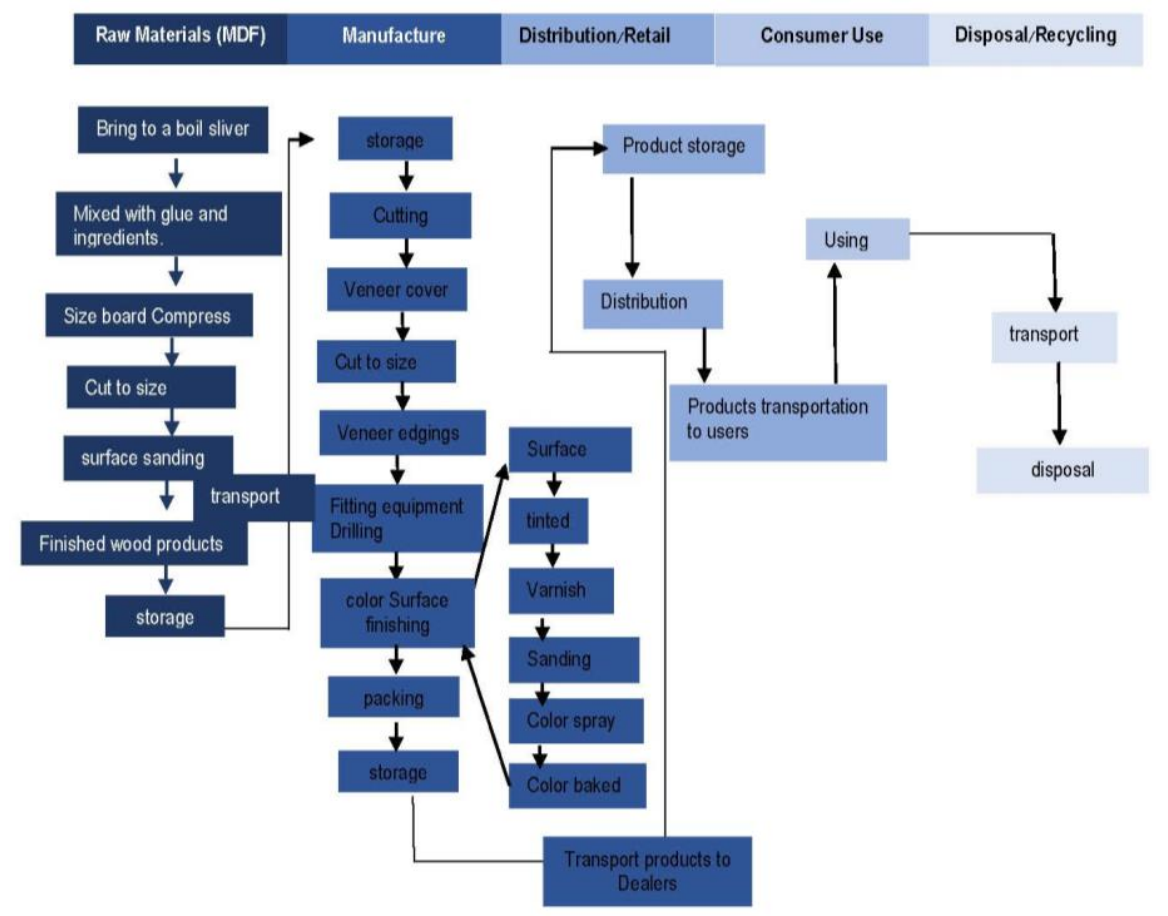

Fig. 3 Steps to assess the carbon footprint of the manufacturing process of the table used the density medium board covered with veneer as the raw material.

3.3 The process of assessing the carbon footprint of the manufacturing process of a table used the medium density board covered with Melamine as the raw material.

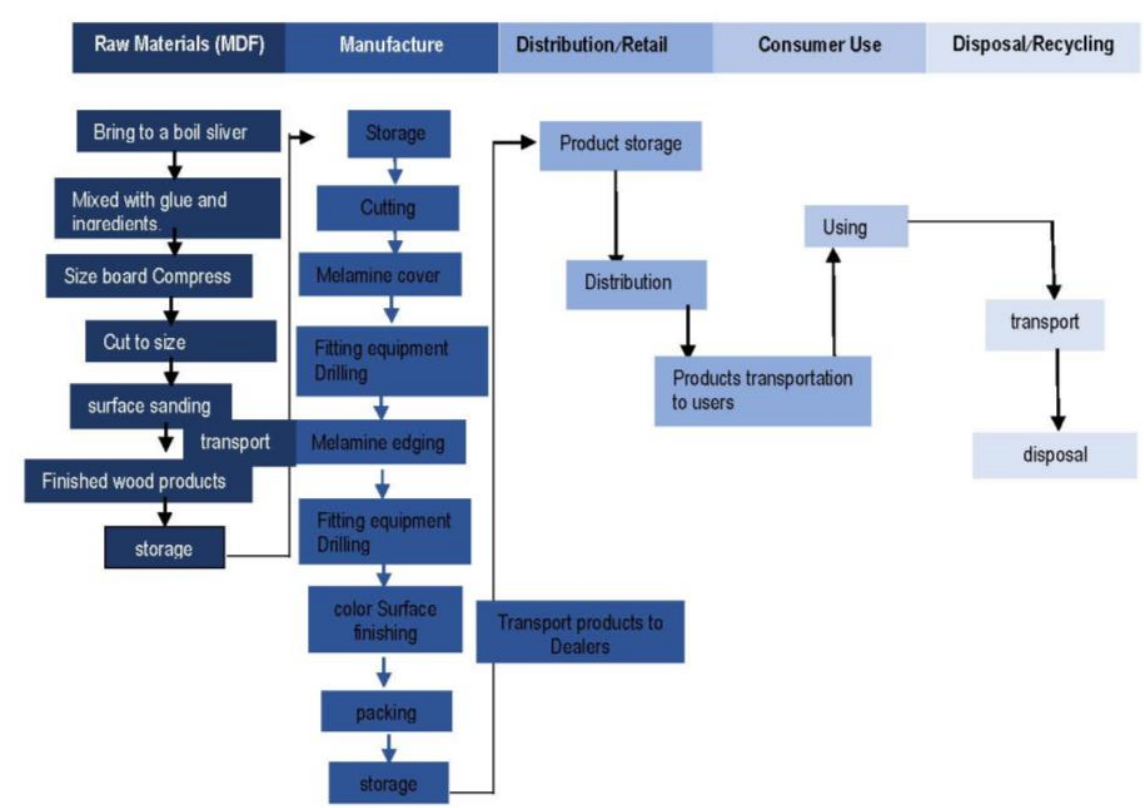

Fig. 4 Steps to evaluate the carbon footprint of the manufacturing process of the table used the medium density board covered with Melamine as the raw material.

3.4 The process of assessing the carbon footprint of the manufacturing process of a table used the medium density board covered with Laminate as the raw material. 


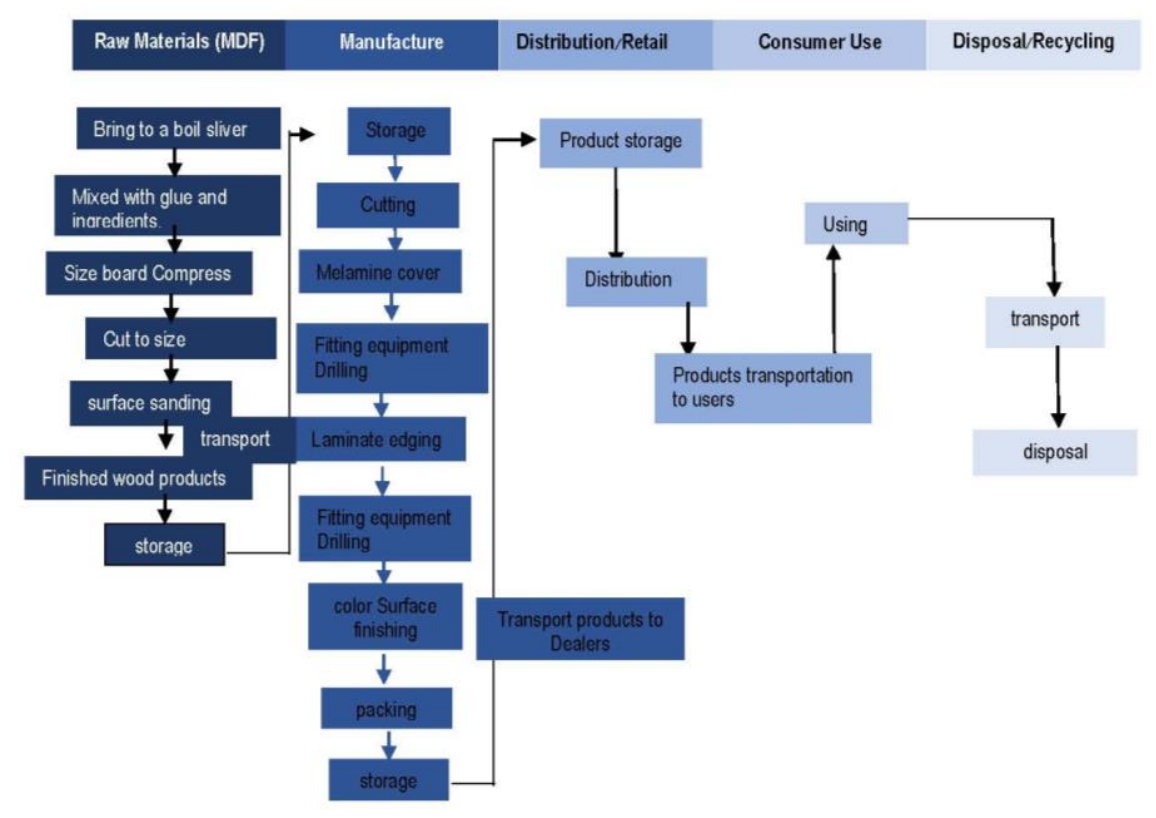

Fig. 5 Steps to assess the carbon footprint of the manufacturing process of the table used the medium density board covered with Laminate as the raw material.

3.5 The process of assessing the carbon footprint of the manufacturing process of the table used the particle board covered with veneer as the raw material.

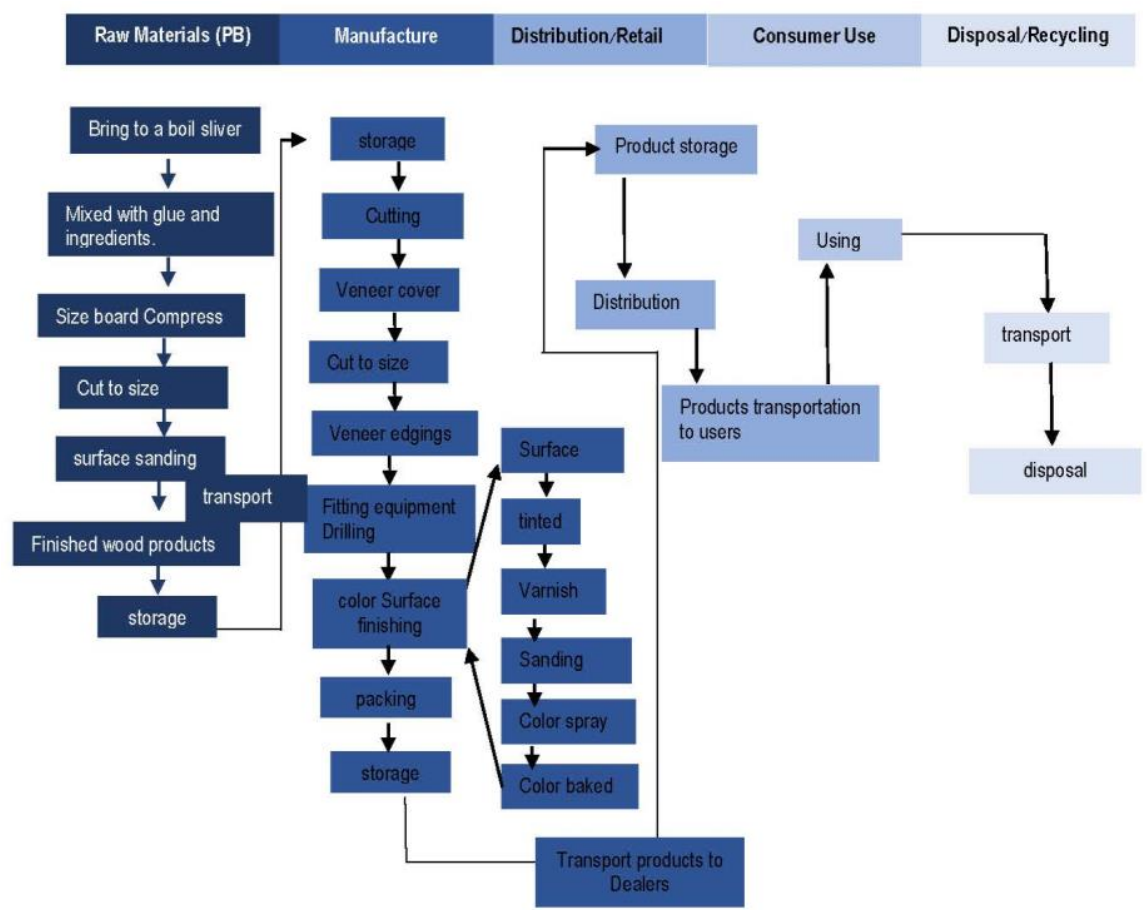

Fig. 6 Steps to assess the carbon footprint of the manufacturing process of the table used the particle board covered with veneer as the raw material. 
3.6 The process of assessing the carbon footprint of the manufacturing process of a table used the particle board covered with Melamine as the raw material.

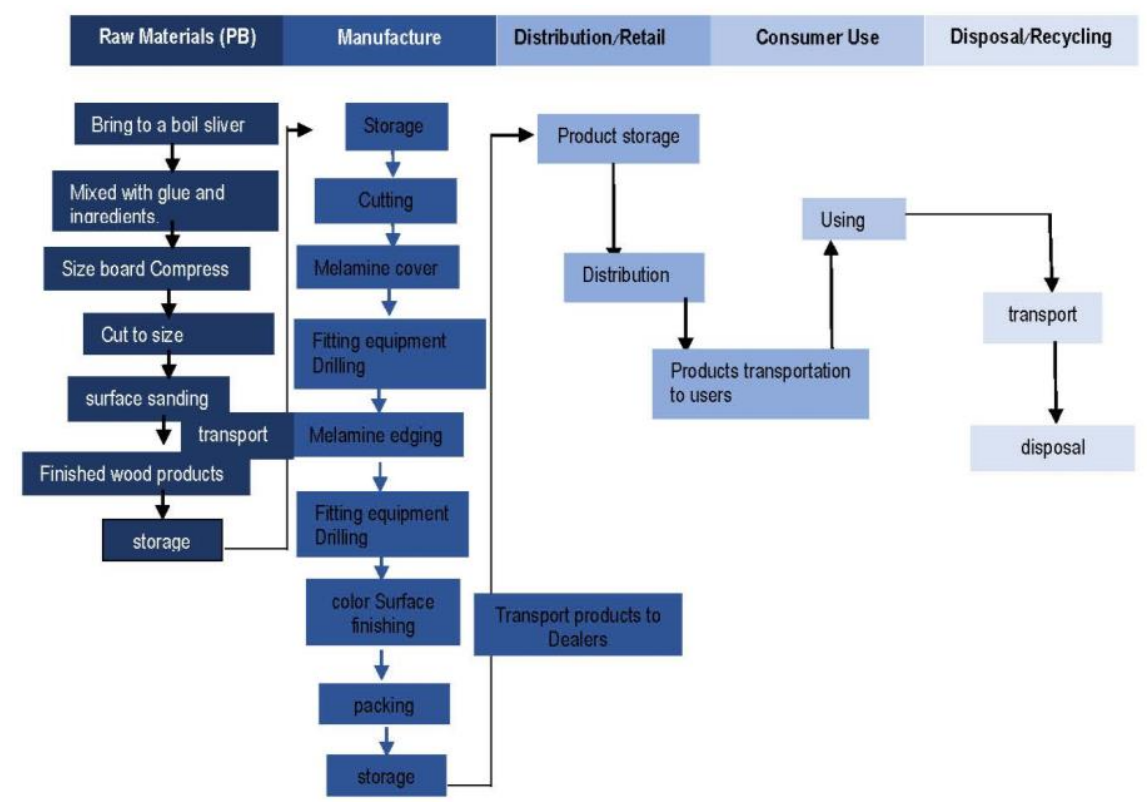

Fig. 7 Steps to assess the carbon footprint of the manufacturing process of the table used the particle board covered with Melamine as the raw material.

3.7 The process of assessing the carbon footprint of the manufacturing process of a table used the particle board covered with laminate as the raw material.

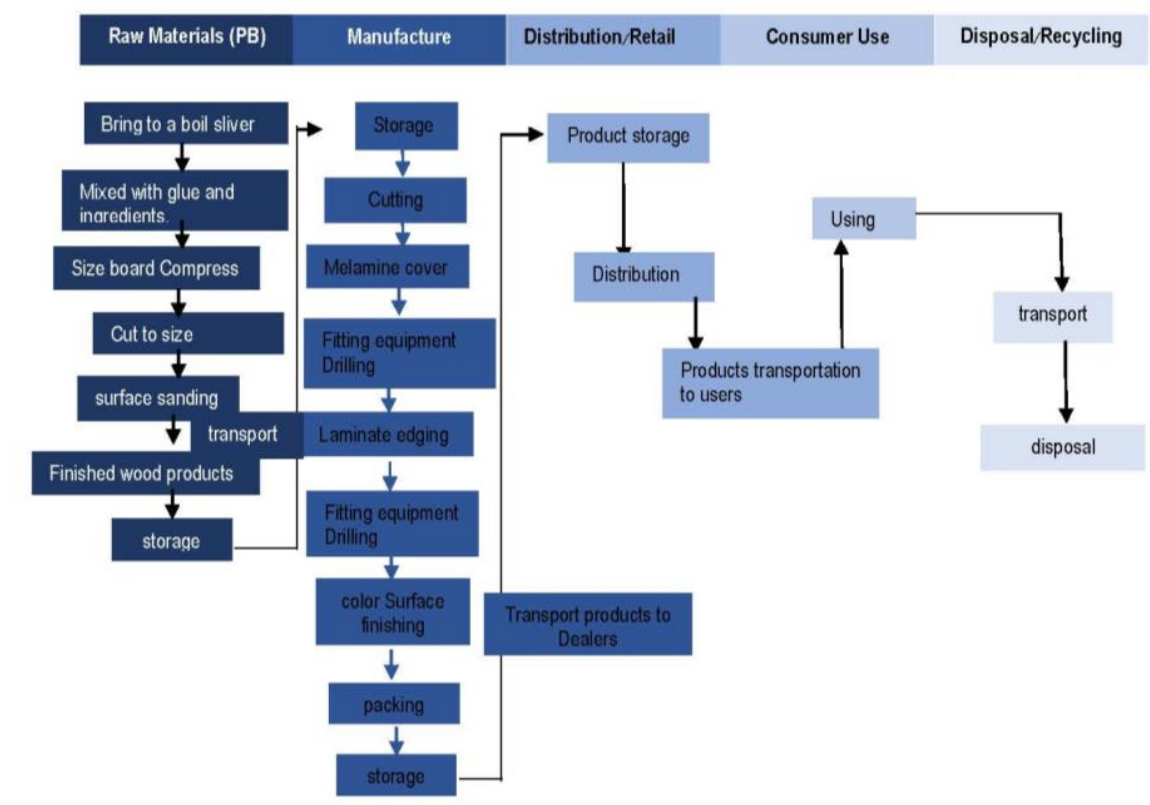

Fig. 8 Steps to assess the carbon footprint of the manufacturing process of the table used the particle board covered with laminate as the raw material.

\subsection{Findings}

The aim of this article is to determine the criteria for selecting low-impact materials for use in desk furniture design. Used as a material for production. Carbon footprint evaluation techniques help in assessing environmental impacts. Of the furniture production process. Focus on the environmental impact of wood panels from the beginning of the manufacturing process to completion. Expected results to be found in this research.

- The boards used in furniture production are expected the particle board to have less impact on the environment than MDF and wood, respectively. 
- The coating process and the surface finish of the furniture are expected laminate to have less environmental impact than the melamine and veneer plates respectively.

\subsection{Discussion and Analysis}

\section{The results are expecting to be discovering.}

This study is the fourth step in the process of analysing the carbon footprint of the manufacturing process of the table. With the different materials used in production. Each style of furniture To find the difference of the carbon footprint of different. As part of the research. The attempt to link the design of furniture that can reduce the environmental impact. Consumer perception and can make furniture that is environmentally friendly. To contribute to the design elements such as the shape, the materials used, which causes the outset of the environmental impact. And the manufacturing process as it contributes to the environmental impact. The energy consumption of production, water use, emissions of carbon dioxide, Racine. And causing waste. (Scientific Applications International Corporation (SAIC) 11251 Roger Bacon Drive Reston, 2006) To assess the impact of environmental issues in this primary research. Will focus on the selection of raw materials. The selection of material for the production of furniture. Manufacturing processes and surface transportation impact on the environment. Using the carbon footprint. To assess the impact that much. And enable consumers to recognise the impact of design and manufacturing. What are the factors that can make consumer awareness and understanding of the environmental impacts that occur And what are the factors that influence the decision to buy furniture The lead elements of design furniture that is environmentally friendly can be conveyed to the consumer perception of environmentally friendly furniture the context of design and production in Thailand? (Promotion, 2011)

The process of assessment the carbon footprint is an important Step primary research. The precision and accuracy in the assessment of the carbon footprint. Researchers expect Assessing the carbon footprint of each style furniture. There will be different levels of carbon footprint low, medium and high to be used as indicators of issues in the field of pattern recognition furniture. To create a tool (stimuli) Principal Investigator for the trial to continue.

The expectation of this research. The environment is the values by consumers as part of a push for green marketing. And Green Consumers Will look to green consumers. An awareness of the environment, or the pursuit of value. Taking into account the social environment, including Earth are life. By willing to pay to buy a product or service that does not damage the environment. The business operations of the operators or managers must be the conscious male consumer. The destination management activities, logistics and supply chain. Otherwise, if a business competition to meet consumer demand for a new breed better. When the success of the business will be a distant possibility. (Energy, 2013) And guide the consumer to participate in reducing greenhouse gas emissions. It is a market mechanism to encourage manufacturers to develop products that reduce greenhouse gas emissions to meet the needs of consumers. However, consumers need to be informed of the decision to buy the product. Promotion Using carbon labelling on products so as to encourage costumers to have greenhouse gas emissions of each product. The decision to purchase the product also adds capabilities. Industry in Thailand with the global trading platform. (Commission, 2011)

The recommendations for the next research. Because the materials used in the production of table furniture. The raw materials had many kinds. And in the case of furniture, carbon footprint should be assessed for furniture other than table furniture, so further research should evaluate the carbon footprint of the materials used in all types of furniture and ultimately to compare the amount of carbon footprint of each material. It is easy and convenient to use as supporting material in the manufacture of eco-friendly furniture by designers. The carbon footprint assessment method relies on product lifecycle assessment techniques to assist in the calculation. It can calculate many environmental impacts, such as water pollution, noise pollution, solid waste, as well as health effects. In the next research, other impacts should be assessed. Especially health That is the closest impact to the population.

\section{Acknowledgements}

I would like to express my sincere thanks to my dissertation advisor, Dr Yanin Rugwongwan and Dr Wichitra Singhirunnusorn for they are the invaluable help and constant encouragement throughout my research.

\section{References}

Commission, E. (2011, October 28). Product Footprinting. Science for Environment Policy DG Environment News Alert Service(28), pp. 1-12.

Energy, D. o. (2013). Thailand Energy Efficiency Situation. Bangkok.

Maria d Bovea, R. v. (2004). Materails selection for sustainable product design: a case study of wood based furniture eco-design. Materails and Design, 25, 111-116. doi:10.1016/j.matdes.2003.09.018

Promotion, D. o. (2011). Community guidelines for the production of products that are labeled carbon. Bangkok: samartcopy Companies Limited.

Rattanawun, M. (2015). Carbon Footprint. Bangkok: Up Aphrodite's Company Limited.

Review, P. L. (2012). The Sustainability Consortium Packaging Working Group. Boston, MA 02110: Sustainable packaging Coalition. 
Schwartz, R. J. (n.d.). International Tradable Cabon Dioxide Permits and Their Appication Under The Kyoto Protocol. In R. J. Schwartz, International Tradable Cabon Dioxide Permits and Their Appication Under The Kyoto Protocol (pp. 80-98). New Haven, Connecticut: Yale School of Forestry and Environmental Studies.

Scientific Applications International Corporation (SAIC) 11251 Roger Bacon Drive Reston, V. 2. (2006, May). Life Cycle Aeesessment: Princioles and Practice. Ohio: National Risk Management Research Laboratory Cincinnati. Retrieved from http://brevard.ffas.ufl.edu/communities/pdf/chapter1_frontmatter_Ica101.pdf

Sergio Silva Braga Junior, D. d. (2015). The Effects of Environmental Concern on Purchase of Green Products in Retail. Procedia - Social and Behavioral Sciences 170, 99 - 108. doi: 10.1016/j.sbspro.2015.01.019 